\title{
Test and Play - A Complex Relationship
}

\author{
Maja Ahler \\ Centre for Sports, Health and Civil Society, Institute of Sports Science and Clinical Biomechanics, Odense, Denmark \\ *Corresponding author: Majaahler@gmail.com
}

Received March 19, 2014; Revised June 13, 2014; Accepted July 01, 2014

\begin{abstract}
Collecting data in relation to an interventional research project (SPACE (School site, Play spot, Active transport, Club fitness and Environment) was developing, documenting, and assessing a comprehensive intervention over 3 years in 14 local school districts to promoted everyday physical activity among 11-15-year-olds adolescents.) a $7^{\text {th }}$ grade boy draw my attention to the combination of test and play with a striking comment. I got interested and wanted to know how the $7^{\text {th }}$ graders experienced these test situations, the one in the beginning and the one in the end of the project? Had they experienced it as test, play or something else? And how did they perceive a relationship between their experiences and their conceptions of test and play? In my study (The study of test and play was the final project of my Masters degree in Sport and Health at University of Southern Denmark, supervised by Professor Henning Eichberg) it appeared how a relation between test and play, according to the pupils' belief of test and play was a combination of two complex contradictions. Through analysis it became clear how the $7 .{ }^{\text {th }}$ graders reflection on their own experiences was about more than test and play. Their narratives and the focus group discussions pointed towards a triadic relationship of test, play and sport.
\end{abstract}

Keywords: play, test, pupils, time, interpersonal relations, objectifications

Cite This Article: Maja Ahler, “Test and Play - A Complex Relationship.” American Journal of Educational Research, vol. 2, no. 7 (2014): 477-479. doi: 10.12691/education-2-7-8.

\section{Test Day}

"Oh no, this game is really the worst play!” The boy said this with jokiness in his voice and grinned all over as he looked at his classmate in the track next to him. They were getting ready for the Anderson running test and did not seem to notice my presence. What he said, and the fact that he said it there, right in the middle of a test day, surprised me. How did this situation remind him of play and how could he feel playful when he was about to be tested? This intrigued my curiosity and I wanted to know about the pupils' perception of test and play. I aspired insight into the pupils' experiences of test and play to comprehend how the tensions between test and play appeared and how it affected them.

\section{Testing}

When testing, we seek to examine, analyse, and question the world around us. Test results needs to be factual data, which often means numbers, as a given test procedure must be repeated in the search of certainty or proof of reality. The condition of play is somewhat different. There is no external obligation to the players of replicating the play and when playing the same over and over again the players have no expectations of it being the exactly same. More likely, every play situation will be new or slightly different from the play first played, and to the pupils this was a part of their conception of how to play. Combining test with the philosophy of play will without a doubt have some influence on the participants' experiences of being tested. Particularly when testing physical activity and fitness of children, project administrators, teachers and other practitioners often refer to the test situation as if it is play [1]. In various settings test and play is combined based on the intention of giving the participants a positive pleasurable experience of being tested. Even though two activities appear understandable and are quiet commonly accepted, combining them can sometimes be inappropriate or confusing to the participants. The relationship between test and play is filled with tensions, and the complexity of the combination makes it impossible to describe the connection in all the details and to completely understand it.

We tend to ask what is play and why do we play, as well as we are tempted to ask what are the complex factors in the composition of play and test and why this combination is so filled with tensions? The problem is that, as soon as we focus on the individual aspects of the relationship, the greater picture is lost. Factuality and verification are often used to reduce complexity, but the complexity of test and play cannot be reduces by these methods. Instead we must seek insight in the participants' experiences of the contradicting tensions they feel when meeting play and test.

\section{Methodological Approach}

Using a phenomenological and narrative approach, one can make the tensions between tests and play visible or 
sensible to the participating pupils. In my study, three classes of $7^{\text {th }}$ grade pupils participated. They told about their experiences from a test of physical activity and how they felt that play was related to this test situation. The $7^{\text {th }}$ graders wrote their own narratives expressing their thoughts on different phenomena related to test and play, and in small focus groups they discussed how the experiences were meaningful to them. Examination of the narratives and the focus groups' conversations revealed interesting configurations of time, interpersonal relations and objectifications. Henning Eichberg points out how bodily movement can be analysed in connection with the cultural patterns appearing as different configurations [2]. By using the configurational analysis, we recognize cultures of the body according to how people move in time, space, energy and interpersonal relation, and it reveals the cultures of production relating to the ways in which people objectify their movements and the objects they produce by moving. Using this approach, we are interested in the occurrence of patterns, as the different configurations never appear as isolated factors but must be understood as related to each other. From the narratives and focus group dialogues, I became aware of how configurations of especially time, interpersonal relations and objectifications were central to the pupils. Even though the patterns relating to test and play seemed to be rather similar, they were experienced as significantly different and sometimes described with contradicting meanings [3]. The $7^{\text {th }}$ graders spoke of test as a way of getting a more objective perspective on the factual reality. In their conception, test was associated with proof, examination, and certainty, and the outcome of a test was accepted as a reliable truth. When observing the pupils, I noticed how they searched for objective verifications in different ways, and in their stories most of them tended to focus on the factual reality as well.

\subsection{Time}

Configurations of time occurred as contradictions between the situative time and chronological time. On the testing day it seemed as if the pupils lost track of time, as they mostly wanted to know how much longer they had to run, and in the narrative texts they relate the present events to their previous experiences of being tested. Focus group discussions revealed distinct difference in the pupils' conception of time. The relationship between test and time had to do with prior expectations, training and a feeling of being ready in time. Contrary to the chronological time of the test, they spoke of the time of play as a situative time. They felt that there was no factual time in play, because play has no past with preparation or no final end as it can go on and on [4].

\subsection{Interpersonal Relations}

Social participation was important to the pupils, and the configurations of their interpersonal relations were distinct in both my observations, in their stories, and in the focus group dialogues. Observing the pupils, I became aware of how they used measurements of their bodily shape and performance to compare themselves to others. The physical body and the bodily performances signified social relationship, status and power [5]. Many of the pupils described in their narrative texts how a test could feel like a competition and how they felt like winning when they performed better than the others. In the focus group dialogues it became clear how the pupils had contradictory understandings of the interpersonal relationship related to test and play. They understood test as showing differences between the participants in a pursuit for sorting them into different groups. The pupils thought of relations in play as being almost opposite to those in a test situation as they associated play with the establishment of community between the players.

\subsection{Objectifications}

All pupils received a personal scorecard to keep track of their results from each of the physical test. Observing the pupils it seemed that they did not consider their subjective feeling of how they performed to be very important. Instead they had more interest in the factual numbers and the objectified status a good result gave them. The results and numbers played a central part in most of the pupils' narrative texts. The words were positive and the tone in their stories of the experience of being tested was confident when they were satisfied with the results. But when the results differed from what they had expected they were negative and tented to blame themselves of failure. According to the focus group discussions, the pupils associated results with both play and test, but in relation to test the results had a different meaning and purpose, than they felt they had in play [6]. When the pupils spoke of test and results, they linked it to time. They needed time to prepare, and they expected the test to have a timeframe with a marked beginning and end. Test results made the bodily differences between the participating pupils visible and marked who was the winner and who was the looser. When playing, the pupils had no need for preparation and they thought of preparation as impossible, because they mostly play by impulse. As they felt that play never really ended, their interest in chronological time was pointless and irrelevant to their play. Objectification of things and factual results only made sense during the process of playing and inside the play community, not afterwards. The pupils had similar feelings concerning the status of the winner or looser: This status was only a part of the play and had no meaning in their everyday life and was not related to "reality".

\subsection{Test, Play - and Sport}

When combining test with the thoughts of play this will without any doubt have some influence on the participants' experiences of being tested. In particular when pupils intelligence or physical activity level and fitness are tested project administrators, teachers and other practitioners have a tendency to refer to test as if it is play. When combining test and play, one thinks, the test is made fun and pleasant, and there for more appealing to the participating children and young people as it is described in terms of play rather than test.

Not knowing for certain if the situation is a test or play, will affects the pupils commitment to the planned activity. One of the consequences might be that the outcome, the results are incorrect, according to the actual test requirements. Although play is played as an earnest and sincerely activity it is not essential for the players to focus 
on details while playing, whereas it is required of the test participants. Without considering how the participants might be affected by a combination of test and play, they might get a wrong impression of the purpose of the situation and feel mislead. These $7^{\text {th }}$ graders knew they were being tested for research, but they got confused, as the situation did not correspond to their expectations of a test. When they thought of test they expected time to prepare, they got nervous about the competition as they could win or loose and they became quite focused on the outcome of the tests: their results.

The $7^{\text {th }}$ graders were given no time to prepare and train for these tests, although preparation in their opinion was an important part of being tested. The lack of training was unexpected and implied a combination of test and play, creating ambivalent tensions in concern to the pupils' interpersonal relationships. The pupils' aspiration to set themselves apart from the others enthused them to consider the tests as competitions with the unofficial nomination of a winner and a looser. This appeared similar to how they were eager to win a competition in sport [7]. In many ways did the feeling of rivaling conflict with the mindset of playing. The pupils mentioned how they knew and valued play by its call for camaraderie, equality and community. When combining test and play the pupils became aware of how the competition turn out to be more than just part of their play. Test results are based on fact in a scientific request for truth of everyday life and reality something that the pupils meant, had no important meaning in play. By pursuing a winner the pupils had to rely on the results, which linked the title as a winner beyond the play and to everyday life as well. The pupils knew that testing also meant measuring, which was a bit distressful to them. Not only were their performances studied in the physical tests but they also felt their bodies were measured as interesting products. Objectifying everything, their bodies as well was correlated to a feeling of being categorized, and this affected the pupils so they concentrate more on producing results, which satisfied them. Concern for product and result more than interest in the process was central to the complexity of relating test and play. The pupils described test as something they in a way 'did to them selves', an obligation that they had to get done with. Almost opposite to test was their thoughts of play as something they 'just did', voluntarily and with joy. The pupils' expressions of draws attention to how combining test and play makes it impossible to fully participate in the activity if it was intended to be both test and play at once [8]. They simply were not able to maintain an equal aspiration for producing results and letting go in the activity process, at the same time.

An arrangement with an unconsidered combination of test and play reveals how professionals and other adults often tend not to value or pay much attention to pupils' opinions. Thereby we may end up showing little respect for the call for seriousness, which these $7^{\text {th }}$ graders meant was relevant in both test and play. In both test and play the pupils spoke about the ability to commit themselves as this made them feel they were really and honestly participating, and linking test and play did, in their experience make this somewhat impossible [9]. Play was in the pupils experience unique and quite distinct from their conception of a test. They associated play with spontaneity and free partaking, friendship, equal community and a feeling of being lost in the moment, which was almost counterpart to how they defined test. In their conception test became more like sport as it included time to prepare or train, competition against others and the interest for great results in a pursuit to be the winner.

\section{References}

[1] Graser, S.V., Sampson, B.B., Pennington, T.T. \& Pursak K.A. (2011). Children's Perception of Fitness Self - Testing, the Purpose of Fitness Testing, and Personal Health. The Physical Educator. Vol. 68(4), p. 175-187.

[2] Eichberg, H. (2001). Thinking contradictions. Towards a methodology of configurational analysis. In: K. Dietrich (ed.) (2001) How Societies Create Movement Culture and Sport. (p. 1032).København: Institut of Exercise and Sport Science.

[3] Møller, J. (2001). Nærvær - forsøg på en nem definition af leg. In: J. Hansen \& T. Skovgaard (2002). Idrctshistorisk Årbog 2001 Sportens væesen og uvæsen”. (s. 141-156) Odense: Syddansk Universitetsforlag.

[4] Kuschner, D. (2012). What is the state of play?.International Journal og Play, Vol.1(1), p. 103-104.

[5] Fingerson, L. (2009). Children's Bodies. In: J. Qvortrup, W.A., Corsaro\& M. Honig (Edt.) (2009). The Palgrave Handbook of Childhood. (p. 217-227) Hampshire: Palgrave Macmillan.

[6] (Evaldsson, A. (2009). Play and Games. In: J. Qvortrup, W.A Corsaro\& M. Honig (Edt.) (2009). The Palgrave Handbook of Childhood.(p. 316-331) Hampshire: Palgrave Macmillan.

[7] Eichberg, H. (2013). Another globality of sport: Towards a differential phenomenology of play and laughter. EAST - East Asian Sports Thoughts. Vol. 3, p.115-137.

[8] (Sutton-Smith, B. (2008). Play Theory. American Journal of Play, Vol. 1(1), p. 82-125.

[9] Huizinga, J. (1950). Homo Ludens, a study of the play element in culture. London: Roy Publishers. 